\title{
Composición bromatológica y degradabilidad ruminal in situ de residuos agroindustriales de maracuyá (Passiflora edulis) y plátano (Musa paradisiaca)
}

\section{Bromatological composition and in situ ruminal degradability of agroindustrial residues of passion fruit (Passiflora edulis) and banana (Musa paradisiaca)}

${ }^{\bullet}$ Italo Espinoza Guerra ${ }^{1}$, Marlene Medina Villacís ${ }^{2}$, Alexandra Barrera-Alvarez ${ }^{1}$, León Montenegro Vivas ${ }^{1}$, Adolfo Sánchez Laiño ${ }^{1}$, Miguel Romero Romero ${ }^{1}$ y Antón García Martínez ${ }^{3}$

${ }^{I}$ Universidad Técnica Estatal de Quevedo. Facultad de Ciencias Pecuarias. Carrera de Ingeniería Zootécnica. Campus Finca Experimental "La María". CP. 121250. Km. 7 1/2 vía El Empalme, cantón Mocache. Los Ríos. Ecuador. •iespinoza@uteq.edu.ec, barreraalvarez@yahoo.com; lmontenegro@uteq.edu.ec; arsanchez@uteq.edu.ec; jromero@uteq.edu.ec

${ }^{2}$ Universidad Técnica Estatal de Quevedo. Facultad de Ciencias de la Ingeniería. Carrera de Ingeniería Agrondustrial. Campus Ing. Manuel Haz Álvarez, km 1.5 vía a Santo Domingo de los Tsáchilas. EC.120501.Quevedo, Ecuador. mmedina@uteq.edu.ec ${ }^{3}$ Universidad de Córdoba. Departamento de Producción Animal. Carretera Madrid-Cádiz, km. 395, 14071 Córdoba, España. pa1gamaa@uco.es

Resumen

$\mathrm{E}$ l objetivo del estudio fue evaluar la degradabilidad ruminal in situ de la materia seca, orgánica e inorgánica de residuos de cáscara de maracuyá, semillas de maracuyá y cáscara de plátano, provenientes de la industria de procesamientos de jugos y alimentos. Se tomaron muestras representativas para determinar la composición química y se utilizó la técnica de degradabilidad in situ a 0, 3, 6, 12, 24, 48 y 72 horas de incubación ruminal. La cáscara y semilla de maracuyá, presentaron mayores valores de materia orgánica (89.46-97.21\%), proteína (16.56-14.55\%), cenizas (10.54 $10.70 \%$ ), fibra detergente neutra $(70.75-63.24 \%)$, menor contenido de fibra detergente ácida (30.73-37.45\%) y grasa bruta $(2.98-4.91 \%)$, en relación a la semilla de maracuyá que presentaron valores inferiores de materia orgánica, proteína bruta, cenizas, fracciones detergente ácida (89.30, 8.16 y $38.87 \%$ ), y valores superiores de grasa bruta y fibra detergente neutra (9.60 y 70.75\%). En la degradabilidad in situ de la materia seca y materia orgánica la cáscara de plátano presentó la mayor $(\mathrm{p}<0.05)$ tasa de degradabilidad en todos los tiempos de incubación. La semilla de maracuyá fue inferior a los demás subproductos y su degradación fue relativamente estable en los diferentes tiempos. La degradabilidad in situ de la materia inorgánica no presento una tendencia estable, se encontraron diferencias $(\mathrm{p}<0.05)$ solo hasta el periodo de incubación de 0-6 horas. En conclusión, los residuos de cáscara y de maracuyá y plátano presentaron mejor valor nutritivo que los residuos de semilla maracuyá.

Palabras clave: alimentos, frutas, residuos agroindustriales, composición química, digestibilidad de los nutrientes.
Rec.: 22.05.2017. Acept.: 20.09.2017.

Publicado el 1 de diciembre de 2017
Abstract

$\mathrm{T}$ he objective of the study was to evaluate the in situ ruminal degradability of the dry, organic and inorganic matter of passion fruit peel residues, passion fruit seeds and banana peel, from the food and juice processing industry. Representative samples were taken to determine the chemical composition and the in situ degradability technique was used at $0,3,6$, 12, 24, 48 and 72 hours of ruminal incubation. The passion fruit peel and seed, presented higher values of organic matter (89.46-97.21\%), protein (16.56-14.55\%), ash (10.54-10.70\%), neutral detergent fiber (70.75-63.24\%), lower fiber content acid detergent (30.73-37.45\%) and crude fat (2.98-4.91\%), in relation to the passion fruit seed that showed lower values of organic matter, crude protein, ash, acid detergent fractions (89.30, 8.16 and 38.87\%), and higher values of crude fat and neutral detergent fiber (9.60 and $70.75 \%)$. In the in situ degradability of the dry matter and organic matter the banana peel had the highest $(p<0.05)$ degradability rate in all the incubation times. The passion fruit seed was inferior to the other by-products and its degradation was relatively stable at different times. The in situ degradability of the inorganic matter did not show a stable tendency, differences were found $(\mathrm{p}<0.05)$ only until the incubation period of $0-6$ hours. In conclusion, shell and passion fruit and banana residues presented better nutritional value than maracuyá seed residues.

Key words: food, fruits, agroindustrial waste, chemical composition, nutrient digestibility. 


\section{Introducción}

$\mathrm{C}$ on el aumento de la diversidad y de la oferta de productos para alimentación humana, el proceso de industrialización de esos alimentos resultó en diversos subproductos, que, por no ser utilizados directamente en la alimentación humana, acabaron convirtiéndose en residuos, como consecuencia de su inadecuada gestión pueden convertirse en productos contaminantes. Una alternativa ante esta problemática podría ser la utilización de estos subproductos en la alimentación animal, especialmente de rumiantes, de esta manera contribuyen a mitigar su acción contaminante y los costos de su gestión (Correia et al., 2006). Una fuente importante de estos residuos agroindustriales lo genera la industria de frutas procesadas, aportando alrededor de un $40 \%$ de los residuos agroindustriales (Bartholo, 1994). La gestión de estos residuos es un gran problema económico, ya que las empresas tienen que asumir los altos costos por la disposición de éstos (Yépez et al., 2008).

Para el uso de los residuos agroindustriales en alimentación animal es necesario el conocimiento de su valor nutritivo (Bertipaglia et al., 2000), además de determinar la viabilidad de su inclusión como fuentes de alimentos alternativos, aunado de cuantificar la respuesta animal en términos de palatabilidad y desempeño productivo $\mathrm{y}$ económico; no obstante, la incorporación de estos residuos agroindustriales en la dieta para animales es escasa, debido principalmente al desconocimiento de su composición bromatológica y los niveles de utilización adecuados en la elaboración de dietas para animales, en especial de rumiantes, así como, su impacto económico y biológico sobre la producción animal (Lousada et al., 2002).

Por lo tanto, los subproductos resultantes de las agroindustrias de gran importancia en nuestro medio (maracuyá y plátano) representan una alternativa interesante de uso en la alimentación de rumiantes, motivo por el cual se planteó el presente trabajo de investigación con el objetivo de determinar la composición química y la degradabilidad ruminal in situ de los residuos agroindustriales de maracuyá y plátano, lo que permitirá determinar su posible utilización en la elaboración de dietas para rumiantes.

\section{Materiales y métodos}

$\mathrm{L}$ a investigación se realizó en el Laboratorio de Rumiología $\mathcal{L}_{\mathrm{y}}$ Metabolismo Nutricional (RUMEN) de la Universidad Técnica Estatal de Quevedo (UTEQ), provincia de Los Ríos, Ecuador. Se utilizaron dos residuos agroindustriales de maracuyá Passiflora edulis (cáscara y semillas), obtenidos de la empresa TROPIFRUTAS S.A. (Quevedo, Ecuador), y residuos de plátano Musa paradisiaca (cáscara), aportado por la planta de alimentos La Oriental S.A. (Quevedo, Ecuador).

\section{Composición química}

En la determinación de la composición química de los residuos agroindustriales se procedió a tomar muestras representativas de $500 \mathrm{~g}$ de cada residuo agroindustrial, en las que se determinaron los contenidos de materia seca (MS), materia orgánica (MO), cenizas y proteína bruta (PB), de acuerdo con los métodos descritos por Association of Official Analytical Chemists (AOAC, 1990), y de fibra neutro detergente (FND) y fibra ácido detergente (FAD), con el procedimiento de ANKOM Technology (Macedon, NY, EUA). Previo al análisis, la muestra de cada residuo agroindustrial se homogenizó y se colocó en una estufa a $65^{\circ} \mathrm{C}$ por 48 horas, para luego ser molidas en un molino (Laboratorio Thomas Willy).con criba de 2 milímetros.

\section{Degradabilidad ruminal in situ de la materia seca (DISMS)}

Se preparó una muestra correspondiente a cada residuo agroindustrial. La muestra se deseco en estufa (Memmert UN55, Memmert, Schwabach, Alemania) a $65^{\circ} \mathrm{C}$ por $48 \mathrm{~h}$. La DISMS se determinó utilizando la técnica de bolsa de nylon en tres bovinos castrados y fistulados del rumen de $400 \mathrm{~kg} \pm \mathrm{de}$ peso vivo. Para cada corrida se utilizaron siete bolsas de nylon 10 x $21 \mathrm{~cm}$ y $53 \mathrm{~mm}$ de tamaño de poro, que contenían cada una $10 \mathrm{~g}$ de muestra molida, seis bolsas se suspendieron en la parte ventral del rumen, con una secuencia de incubación de $0,3,6,12,24,48$ y 72 h. La desaparición del material en la hora cero, fue estimada en la séptima bolsa sin incubar en el rumen, lavándola de la misma manera que las demás. Durante la prueba los bovinos fueron alimentados con pasto saboya a libre acceso. Posteriormente las bolsas fueron secadas en una estufa a $60{ }^{\circ} \mathrm{C}$ durante $48 \mathrm{~h}$; el residuo de cada bolsa en cada periodo de incubación se determinó su contenido de MS, cuyo porcentaje de desaparición se estimó por diferencia utilizando la ecuación de Orskov y McDonald (1980). Los parámetros no lineales, así como la desaparición DISMS, fueron calculados por medio del paquete computacional SAS (2004).

\section{Resultados y discusión}

\section{Composición bromatológica}

La composición bromatológica de los residuos agroindustriales de maracuyá y plátano (Cuadro 1) resultaron similares en el contenido de materia seca total, materia orgánica, materia inorgánica y fibra detergente ácida. La composición química de un alimento es solamente indicativa de su contenido de nutrientes, mas no de su disponibilidad para el animal, y es necesario contar además con datos de digestibilidad (Shimada, 2003). 
Cuadro 1. Composición química de residuos agroindustriales de maracuyá (Passiflora edulis) y plátano (Musa paradisiaca)

\begin{tabular}{lccc}
\hline Contenido & $\begin{array}{c}\text { Cáscara de } \\
\text { maracuyá }\end{array}$ & $\begin{array}{c}\text { Cáscara de } \\
\text { plátano }\end{array}$ & $\begin{array}{c}\text { Semilla de } \\
\text { maracuyá }\end{array}$ \\
\hline MSP & 15.10 & 13.50 & 90.00 \\
MST & 98.86 & 99.56 & 93.88 \\
MO & 89.46 & 89.30 & 97.21 \\
MI & 10.54 & 10.70 & 2.79 \\
PB & 14.55 & 8.16 & 16.56 \\
GB & 2.98 & 4.91 & 9.60 \\
FDN & 63.24 & 45.11 & 70.75 \\
FDA & 37.45 & 38.87 & 30.73 \\
\hline
\end{tabular}

MSP: Materia seca parcial; MST: Materia seca total; MO: Materia orgánica; MI: Materia inorgánica ; PB: Proteína bruta; GB: grasa bruta; FB: fibra bruta; FDN: Fibra detergente neutra fiber); FDA: Fibra detergente ácido

\section{Degradabilidad in situ de la materia seca}

La degradabilidad in situ de la materia seca de los residuos agroindustriales de maracuyá y plátano se presentan en el Cuadro 2. El porcentaje de degradabilidad in situ de la MS del residuo agroindustrial de plátano fue superior $(\mathrm{P}<0.05)$, en todos los tiempos de incubación, logrando valores superiores al $80 \%$ a las $72 \mathrm{~h}$ de incubación, le sigue la cáscara de maracuyá que alcanzó el $78 \%$ de degradabilidad al mismo tiempo de incubación, respuesta contraria se observó en la semilla de maracuyá, residuo que no logró superar el $50 \%$ de degradabilidad a las $72 \mathrm{~h}$ de incubación (Cuadro 2). Estos resultados observados en la cáscara de plátano pueden deberse principalmente al bajo contenido de FDN, un indicador indirecto de la digestibilidad (Gallardo y Gaggíotti, 2004). Los resultados obtenidos con la cáscara de maracuyá, fueron superiores a los reportados por Moncao et al. (2014), quienes reportan $76.01 \%$ a las $72 \mathrm{~h}$ de incubación, respuesta contradictoria con lo señalado por Gallardo y Gaggiotti (2004), ya que este residuo posee altos niveles de FDN.

\section{Degradabilidad in situ de la materia orgánica}

La digestibilidad in situ en porcentaje de la MO de la cáscara de plátano difiere significativamente $(\mathrm{p}<0.05)$

Cuadro 2. Degradabilidad in situ de los residuos agroindustrial es de maracuyá (Passiflora edulis) y plátano (Musa paradisiaca)

\begin{tabular}{ccccccc}
\hline $\begin{array}{c}\text { Incubación } \\
\text { ruminal } \\
\text { (horas) }\end{array}$ & $\begin{array}{c}\text { Cáscara de } \\
\text { maracuyá }\end{array}$ & $\begin{array}{c}\text { Cáscara de } \\
\text { plátano }\end{array}$ & $\begin{array}{c}\text { Semilla de } \\
\text { maracuyá }\end{array}$ & EEM & CV & P< \\
\hline 0 & $35.46 \mathrm{~b}$ & $45.76 \mathrm{a}$ & $23.67 \mathrm{c}$ & 0.83 & 7.12 & 0.001 \\
3 & $38.22 \mathrm{~b}$ & $50.12 \mathrm{a}$ & $32.38 \mathrm{c}$ & 0.56 & 4.17 & 0.001 \\
6 & $41.12 \mathrm{~b}$ & $53.92 \mathrm{a}$ & $36.00 \mathrm{c}$ & 0.51 & 3.58 & 0.000 \\
12 & $57.24 \mathrm{~b}$ & $68.52 \mathrm{a}$ & $38.16 \mathrm{c}$ & 0.87 & 4.77 & 0.000 \\
24 & $74.09 \mathrm{~b}$ & $80.15 \mathrm{a}$ & $39.65 \mathrm{c}$ & 0.13 & 0.61 & $<.0001$ \\
48 & $74.94 \mathrm{~b}$ & $87.50 \mathrm{a}$ & $40.64 \mathrm{c}$ & 0.09 & 0.43 & $<.0001$ \\
72 & $78.75 \mathrm{~b}$ & $89.05 \mathrm{a}$ & $41.09 \mathrm{c}$ & 0.99 & 4.27 & $<.0001$ \\
\hline
\end{tabular}

EEM: Error Estándar de la Media, $\mathrm{P}<$ : Probabilidad, CV: Coeficiente de Variación, abc Medias en la fila con letras iguales no difieren estadísticamente (Tukey $\mathrm{p}>0.05$ ). 
Cuadro 3. Degradabilidad in situ de la materia orgánica de los residuos agroindustriales de maracuyá (Passiflora edulis) y plátano (Musa paradisiaca)

\begin{tabular}{cccccccc}
\hline $\begin{array}{c}\text { Incubación } \\
\begin{array}{c}\text { Ruminal } \\
\text { (horas) }\end{array}\end{array}$ & $\begin{array}{c}\text { Cáscara de } \\
\text { Maracuyá }\end{array}$ & $\begin{array}{c}\text { Cáscara de } \\
\text { Plátano }\end{array}$ & $\begin{array}{c}\text { Semilla de } \\
\text { Maracuyá }\end{array}$ & EEM & CV & P< \\
\hline 0 & $30.06 \mathrm{~b}$ & $40.47 \mathrm{a}$ & $21.86 \mathrm{c}$ & 0.88 & 8.66 & 0.003 \\
3 & $33.80 \mathrm{~b}$ & $45.08 \mathrm{a}$ & $30.67 \mathrm{~b}$ & 0.60 & 5.03 & 0.001 \\
6 & $36.36 \mathrm{~b}$ & $48.08 \mathrm{a}$ & $34.33 \mathrm{~b}$ & 0.53 & 4.07 & 0.001 \\
12 & $53.61 \mathrm{~b}$ & $65.51 \mathrm{a}$ & $36.59 \mathrm{c}$ & 0.86 & 4.99 & 0.000 \\
24 & $71.22 \mathrm{~b}$ & $78.45 \mathrm{a}$ & $38.01 \mathrm{c}$ & 0.09 & 0.46 & $<.0001$ \\
48 & $72.26 \mathrm{~b}$ & $86.66 \mathrm{a}$ & $38.59 \mathrm{c}$ & 0.12 & 0.56 & $<.0001$ \\
72 & $76.58 \mathrm{~b}$ & $88.33 \mathrm{a}$ & $39.20 \mathrm{c}$ & 1.10 & 4.88 & 0.000 \\
\hline
\end{tabular}

EEM: Error Estándar de la Media, $\mathrm{P}<$ : Probabilidad, CV: Coeficiente de Variación, abc Medias en la fila con letras iguales no difieren estadísticamente (Tukey $\mathrm{p}>0.05$ ).

en todas las horas de incubación, comparada con la degradabilidad de la cáscara y semilla de maracuyá (Cuadro $3)$.

Los resultados obtenidos de la cáscara de plátano (Cuadro 3) en la degradabilidad de la MO (88.33\%) a las 72 $\mathrm{h}$ de incubación $(\mathrm{p}<0.05)$ puede deberse al menor contenido de FDN (expuesto en el Cuadro 1), en comparación con los residuos de maracuya, asi, la FDN favorece la actividad de las bacterias celulíticas del rumen, promoviendo un aumento en la digestibilidad de los nutrientes (Bueno et al. 2000); Sin embargo, Bandeira (1995), reporta menor porcentaje (62.99\%) de digestibilidad in situ de la MO de residuos de piña, empleados como única dieta en ovinos.

Degradabilidad in situ de la materia inorgánica

La proporción de materia inorgánica, se considera representativa de los componentes inorgánicos del alimento, sin embargo, pueden incluir productos de origen orgánico como azufre y fósforo de las proteínas, en tanto, pueden producirse pérdidas de sustancias volátiles durante la combustión, como sodio, cloruros, potasio, fóforo y azufre. Entonces, este indicador no es totalmente representativo del material inorgánico de los alimentos, lo cual, su medida es solo aproximada (McDonald et al., 2006).

En el periodo de incubación, la degradabilidad de la materia inorgánica fue similar $(\mathrm{p}>0.05)$ en los tres subproductos (Cuadro 4) a partir de las 12 a 72 horas de incubación con $98.16,95.08$ y $97.06 \%$ para cáscara de maracuyá, cáscara de plátano y semilla de maracuyá, en su orden.

Cuadro 4. Degradabilidad in situ de la materia inorgánica de los residuos agriundustriales de maracuyá (Passiflora edulis) y plátano (Musa AAB)

\begin{tabular}{ccccccc}
\hline $\begin{array}{c}\text { Incubación } \\
\text { Ruminal } \\
\text { (horas) }\end{array}$ & $\begin{array}{c}\text { Cáscara de } \\
\text { Maracuyá }\end{array}$ & $\begin{array}{c}\text { Cáscara de } \\
\text { Plátano }\end{array}$ & $\begin{array}{c}\text { Semilla de } \\
\text { Maracuyá }\end{array}$ & EEM & CV & P< \\
\hline 0 & $79.16 \mathrm{~b}$ & $87.59 \mathrm{a}$ & $78.65 \mathrm{~b}$ & 0.87 & 3.19 & 0.023 \\
3 & $80.64 \mathrm{~b}$ & $90.68 \mathrm{a}$ & $83.50 \mathrm{~b}$ & 0.8 & 2.85 & 0.016 \\
6 & $82.98 \mathrm{c}$ & $93.47 \mathrm{a}$ & $89.10 \mathrm{~b}$ & 0.47 & 1.61 & 0.002 \\
12 & $90.09 \mathrm{a}$ & $94.35 \mathrm{a}$ & $92.66 \mathrm{a}$ & 1.06 & 3.44 & 0.354 \\
24 & $95.92 \mathrm{a}$ & $94.58 \mathrm{a}$ & $93.92 \mathrm{a}$ & 0.53 & 1.67 & 0.384 \\
48 & $97.25 \mathrm{a}$ & $94.74 \mathrm{a}$ & $94.46 \mathrm{a}$ & 0.49 & 1.47 & 0.128 \\
72 & $98.16 \mathrm{a}$ & $95.08 \mathrm{~b}$ & $97.06 \mathrm{ab}$ & 0.23 & 0.73 & 0.015 \\
\hline
\end{tabular}

EEM: Error Estándar de la Media; P<: Probabilidad; CV: Coeficiente de Variación; abc Promedios en cada fila con letras iguales no difieren estadísticamente (Tukey $p>0.05$ ) 


\section{Conclusiones}

$\mathrm{E}^{-1}$ n la composición química, los subproductos de maracuyá, presentaron los valores más altos de materia orgánica, proteína bruta y fibra detergente neutra, además menor contenido de fibra detergente ácida. En la degradabilidad in situ de la materia seca y materia orgánica los residuos de cáscara de plátano tuvieron la mayor tasa de degradación en todos los tiempos de incubación. Mientras, la degradabilidad in situ de la materia inorgánica fue para la cáscara de maracuyá.

\section{Bibliografia}

ANKOM Technology (2008). In vitro True Digestibility with DAISY II Incubator. ANKOM Technology, Macedon, NY.

AOAC. (1990). Official Methods of Analysis (13ra ed.). Washington, EUA: Association of Official Analytical Chemists.

Bandeira, A. (1995). Valor nutritivo do feno de resíduo agroindustrial do abacaxi (Ananas comonus L. Mer.) na alimentação de ovinos. Areia: Universidade Federal da Paraíba, 1995. 59p. Dissertação (Mestrado em Produção Animal) - Universidade Federal da Paraíba.

Bártholo, F. (1994). Perdas e qualidade preocupam. InformeAgropecuário, Belo Horizonte, 17(179), 3.

Bertipaglia, L., Alcalde, C., Siqueira, G., Melo, G. y Andrade, P. (2000). Degradação in situ da matéria seca, proteína bruta e fibra emdetergente neutro de silagens de milho e do resíduo da extração do suco de maracujá Acta Scientiarum 22(3), 765-769.

Bueno, MS., Biachini, D., Leinz, FF., Carvalho, CF., Ferrari, E. (2000). Polpa cítrica deshidratada como substituto do milho em dietas para caprinos em crescimento (Dehydrated citric pulp as corn replace in goats growing diets). In: Reuniao Anual da Sociedade Brasileira de Zootecnia, SBZ, Vicosa-MG, (37), 471.

Ceballos, A., Noguera, R., Bolívar, D., \& Posada, S. (2008). Comparación de las técnicas in situ de los sacos de nylon e in vitro (DaisyII) para estimar la cinética de degradación de alimentos para rumiantes. 20(108).
Correia, M., Costa, R., Silva, J., Carvalho, F. y Medeiros, A. (2006). Utilização de resíduo agroindustrial de abacaxi desidratado em dietas para caprinos em crescimento: digestibilidade e desempenho. Revista Brasileira de Zootecnia, 35(4, Suppl. ), 1822-1828.

Gallardo, M., \& Gaggíotti, M. (2004). Examen a los índices: Diagnóstico de la calidad los forrajes conservados y cómo interpretar los análisis. Sitio Argentino de Producción Animal, 1-3.

Lousada, JE., Correia da Costa, JM., Miranda, JN. \& Rodriguez, NM. (2006). Caracterização físico-química de subprodutos obtidos do processamento de frutas tropicais visando seu aproveitamento na alimentação animal. Revista Ciência Agronômica, 37(1). 70-76

McDonald, P., Edwards, R., Greenhalf, J., \& Morgan, C. (2006). Nutrición Animal (Sexta ed.). (R. Sanz, Trans.) Zaragoza, España: Acribia, S.A.

Monçao, F., Reis, S., Rigueira, J., Sales, E., Antunes, A., Oliveira, E., \& Carvalho, Z. (2014). Degradabilidade ruminal da matéria seca e da FND da casca de banana tratada com cal virgem. Revista de Ciências Agrárias, 37(1), 42-49.

Orskov, E., \& Deb Hovell, F. M. (1980). Uso de la técnica de la bolsa de nylon para la evaluación de los alimentos. Producción Animal Tropical 5: 213-233. Producción Animal tropical, 5, 213-233.

SAS. Versión 9.0. (2004). User's guide. Cary, Estados Unidos.

Togashi, C., Fonseca, J., Soares, R., Gaspar, A., \& Detmanm, E. (2007). Composição em ácidos graxos dos tecidos de frangos de corte alimentados com subprodutos de maracujá. Revista Brasileira de Zootecnia, 36(6), 2063 2068.

Shimada, A. (2003). Nutrición Animal (Primera ed.). México: Trillas, S.A.

Yépez, S., Naranjo, L. y Sánchez, F. (2008). Valorización de residuos agroindustriales frutas en Medellín y el sur del valle del Aburrá, Colombia. Revista Facultad Nacional Agraria Medellín 61(1), 4422-4431. 